DOI: $\underline{10.17805 / g g z .2021 .2 .3}$

\title{
Проблемы понимания результатов генетической диагностики клиницистами*
}

\author{
А. Г. Шестак
}

Российский научный центр хирургии им.

академика Б. В. Петровского, г. Москва;

С. Ю. Шевченко

Институт философии РАН, г. Москва;

В. А. Румяниева

Российский научный центр хирургии им.

академика Б. В. Петровского, г. Москва

Проблема понимания генетических терминов неспециалистами исследована достаточно широко. Однако до сих пор малоизученныли остаются проблемы понимания и интерпретачии врачами-клиницистами результатов генетической диагностики. Основная часть данной статьи содержит описание собственного опыта решения вопросов непонимания результатов генетических исследований со стороны врачей-клинииистов, предложенное сотрудницей генетической лаборатории А. Г. Шестак. В начальных разделах статьи философом науки С. Ю. Шевченко представлены варианты теоретического разворачивания изложенных проблем. В статье последовательно представлены: 1) контекст институций и практик, в котором разворачиваются проблемы понимания; 2) авторская типология этих проблем. В последнем разделе намечены пути решения этих вопросов.

Ключевые слова: понимание; проблемы понимания; генетический термин; коммуникаџия; образование; генетическая лаборатория; генетическая клиника; медико-генетическое консультирование

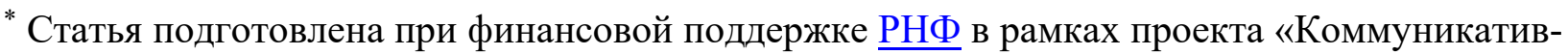
ный контур биомедицинских технологий (на примере геномной медицины)» (№ 18-7810132).

The article was prepared with financial support from the Russian Science Foundation (project "Communicative Outline of Biomedical Technologies (The Case of Genome Medicine)"; no. 1878-10132).
} 


\title{
Issues of Understanding the Results of Genetic Diagnostics by Clinicians
}

\author{
A. G. Shestak \\ Petrovsky National Research Centre of Surgery, Moscow; \\ S. Yu. Shevchenko \\ Institute of Philosophy, Russian Academy of Sciences, Moscow; \\ $V$. A. Rumyantseva \\ Petrovsky National Research Centre of Surgery, Moscow
}

The problem of understanding genetic terms by non-specialists has been studied quite extensively. However, the issues of understanding and interpreting the results of genetic diagnostics by clinicians remain insufficiently explored. The main part of this article is an account of an experience in solving the problems of misunderstanding of genetic results on the part of clinicians, described by a researcher, Anna G. Shestak, who works in a genetic laboratory. In the opening sections of the article, the philosopher of science Sergei Yu. Shevchenko provides options for theoretical development of the issues. The article consistently presents 1) the context of institutions and practices in which the problems of understanding unfold and 2) the authors' own typology of these problems. In the last section, ways of solving these issues are outlined.

Keywords: understanding; issues of understanding; genetic term; communication; education; genetic laboratory; genetic clinic; medical and genetic counseling

\section{ВВЕДЕНИЕ}

За последние 30 лет генетические понятия стали одним из центральных объектов социальных и гуманитарных исследований науки и технологии. В качестве источника драматических изменений в социальной и политической жизни рассматриваются не столько новые медицинские молекулярно-биологические технологии, сколько сами генетические концепты. За этими громкими дискуссиями о социальных значениях успехов генетики и геномики (Nowotny, Testa, 2010) несколько скрытыми остаются обсуждения тех ролей, которые играют эти понятия в системе биомедицинского знания, и тех проблем, которые возникают из-за различий в их понимании среди представителей разных сфер биологии и медицины.

Данная статья возникла из рефлексии сотрудницы генетической лаборатории (А. Г. Шестак) по поводу собственного опыта решения проблем непонимания результатов ее работы со стороны врачей-клиницистов. Основные разделы статьи подготовлены ей. В них последовательно представлены кон- 
текст институций и практик, в котором разворачиваются проблемы понимания, и собственная типология этих проблем. В последнем разделе работы намечены пути решения этих проблем, в том числе и те, к которым удалось прибегнуть в рамках реализации проекта РНФ «Коммуникативный контур биомедицинских технологий (на примере геномной медицины)».

Во вводных разделах, подготовленных специалистом в сфере биоэтики и философии науки С. Ю. Шевченко, те вопросы, которые ставит перед собой А. Г. Шестак, помещены в теоретическую рамку и (разумеется, приблизительно) сформулированы на языке философии и социальных исследований науки и технологии. В разделе с выводами то же самое проделано с итогами, к которым удалось прийти А. Г. Шестак.

\section{ВАРИАНТЫ ПОСТАНОВКИ ПРОБЛЕМЫ}

На обыденном языке рассматриваемая в статье коммуникативная проблема может быть сформулирована достаточно просто «Врачи-клиницисты (негенетики) не понимают (или неверно понимают) те сведения, которые им сообщает генетическая лаборатория». Эти сведения касаются постановки диагноза и назначения лечения для конкретных пациентов, поэтому ее решения имеет очевидное практическое значение.

Попытаемся теоретически развернуть эту проблему, по возможности используя минимум специальной философской терминологии для того, чтобы эта статья оставалась пригодна для чтения врачами и сотрудниками генетических лабораторий. Представляется, что такое теоретическое разворачивание можно предпринять в нескольких направлениях, которые как минимум не полностью исключают друг друга.

Во-первых, можно задаться вопросом о том, что означает слово «понимание», использованное в отношении понятий наук о природе. Базовое для неокантианства различение наук на понимающие, гуманитарные, и объясняющие, естественные, срабатывает при такой постановке вопроса неожиданным образом. Классические науки о природе, о которых и говорили жившие в ХІХ в. неокантианцы, предполагают каузальное, исходящее из причин, объяснение уже случившихся событий. Эти события могут быть искусственно вызваны экспериментальным вмешательством, но при этом объяснение успеха или неуспеха эксперимента всегда ретроспективно. Однако само это объяснение опирается на уже понятое, на отдельные понятия и на их системы. П. Д. Тищенко, рассматривая процесс понимания естественнонаучной статьи, говорит об «историческом» начале и конце этого процесса (Тищенко, 2011). Разделы статьи - введение (с обзором современного состояния проблемы) и заключение (с обсуждением полученных результатов) как бы окаймляют индивидуальное по- 
знавательное предприятие. В этом смысле понимание единицы естественнонаучного знания дважды ретроспективно - и в плане связывания нового знания с уже имеющимся, и в плане оперирования уже устоявшимися понятиями.

Геномная медицина в отличие от классического естествознания зачастую имеет дело не с произошедшими, а событиями, которые, возможно, произойдут в будущем. Непонимание прогноза может быть связано и с непониманием его вероятностной природы, и с непониманием его содержания. Необходимость усвоения смысла предсказания требует применения понимающего подхода в рамках естественнонаучных практик. Уникальность спрогнозированного будущего события, его индивидуальный медицинский смысл врач может ухватить, только лично воспринимая личность больного. В этом смысле понимание медико-генетического прогноза оказывается гораздо шире понимания специфики работы генов.

В плане философии науки можно заметить попытки соотнести наши глубинные представлений о причинности и определенности с одной стороны, и необходимость моделировать молекулярные взаимодействия, происходящие в живой клетке. Часто при объяснении молекулярно-биологических процессов в рамках обучения понятия каскадов или сигнальных путей вытесняются ради простоты единым понятием молекулярного механизма. Однако, как считает философ науки Л. Росс, вместе с таким упрощением теряется базовое различие в типах причинности (каузальности) заложенных в этих понятиях (Ross, 2021).

Второй вариант постановки проблемы позволяет рассматривать непонимание как отказ понимать. В самом категоричном варианте ее можно сформулировать так: представители клинической медицины вынуждены отстаивать дисциплинарные границы своих знаний, а также институциональные рамки своих компетенций. Поэтому они отказываются впускать генетические понятия в свои коммуникативные поля. Теоретических обоснований такого подхода можно предложить сразу несколько. Например, в рамках обсуждения перспектив персонализированной медицины активно развивалась концепция «генетизации» медицины, позволяющей рассматривать непонимание в оптике, близкой к куновским парадигмам (Weiner et al., 2017). С другой стороны, можно начать и с социальных исследований науки и технологии, близких к критической школе. Генетические понятия и указание на конкретные генетические факторы развития заболеваний заставляют врачей и пациентов поиному понимать природу патологии, назначать другое лечение и т. д. (Navon, 2020). Классификация заболеваний является ядром медицинских знаний и практик, различие генетических факторов и молекулярно-биологических механизмов развития патологии предполагают ее пересмотр. Соответственно, врачи-клиницисты могут опасаться возникновения хаоса в сфере своих профессиональных практик. 
Самостоятельные линии такой тяготеющей к социологии и антропологии науки проблемы непонимания могут быть развернуты в рамках концепции «зон обмена» П. Галисона или координации медицинских онтологий А. Мол. В контексте первой из них медицинская генетика сама может выступать «зоной обмена» между разными подходами к классификации заболеваний. Например, она может стать площадкой согласования разных подходов к определению расстройств аутистического спектра (Navon, Eyal, 2014).

Впрочем, чаще генетическая онтология заболеваний, не относящихся только к компетенции врача-генетика, рассматривается как одна из конкурирующих оптик, используемых при их диагностике и лечении. Так, сердечнососудистые патологии, в чьем развитии заметную роль играет наследственный фактор, могут рассматриваться и в оптике их возможного хирургического лечения, и в оптике их терапевтической компенсации (Широков, 2019). Связывание этих линий вместе в идеале должно приводить к формированию мультидисциплинарной команды, но часто этого не происходит. Впрочем, занятые лечением атеросклероза врачи разных специальностей, описанные в работе А. Мол, также, в обыденном смысле, не понимают друг друга (Mol, 2002). Они лишь согласованно взаимодействуют, что в принципе возможно и между агентами, лишенными широких языковых возможностей (например, пастушьими собаками). Кроме того, ограничение взаимодействия «координацией» онтологий подталкивает нас к убеждению, что человек может действовать только в одной онтологии. Вероятно, к медицинским практикам ближе образ стереоскопического взгляда, предложенный У. Селларсом (Sellars, 1962). Согласно ему, человек одновременно воспринимает и толкует мир и в рамках научной онтологии (системы понятий), и в рамках онтологии обыденного мира. Ничего не мешает человеку работать сразу с несколькими системами понятий, а врачам «встречаться» на уровне обыденного мира пациента - его страданий, проблем, целей и ценностей.

Однако представленный А. Г. Шестак практический казус, кажется, можно достаточно полно охарактеризовать понятием «экспликация», в том смысле, в каком оно употреблено у Р. Карнапа (Carnap, 1959). Этот третий вариант теоретического разворачивания проблемы видится мне (С. Ю. Шевченко) наилучшим, поскольку предлагает регулятивный идеал коммуникативных практик, направленных на понимание. Экспликация решает три основных задачи: собственно прояснения, избавления от бессмысленных выражений и достижения верифицируемости (Cappellen, 2018). Т. е. в нашем случае проясняется медицинский смысл молекулярно-биологических терминов. Соответственно, взаимно понятные термины позволяют делать проверяемые суждения. Если эти суждения являются руководством для действия, то именно из хода действий можно сделать вывод о понимании или непонимании. Такими 
действиями могут быть, например, назначение лечения или постановка диагноза, интерпретируя которые можно сделать выводы о понимании или непонимании клиницистом результатов, полученных генетической лабораторией ${ }^{1}$. Соответственно, я предлагаю читать предложенный ниже опыт (взаимопонимания) именно в этой оптике, удерживая в уме две других.

\section{ЧTO TAKOE \\ ГЕНЕТИЧЕСКАЯ ЛАБОРАТОРИЯ?}

Генетическая лаборатория - учреждение или отдел, которое занимается проведением генетических исследований. В основном генетические исследования представляют собой изучение ДНК - химического соединения, которое содержит клетки тела человека и может рассматриваться как «инструкция» для роста, развития и функционирования организма (Что происходит ..., б/д: Электронный ресурс).

Сегодня генетические лаборатории имеют многопрофильные федеральные медицинские центры, медико-генетические научные центры, частные клиники. Бывает, что лаборатории специализируются на изучении и диагностике только определенных наследственных заболеваний, так как генетических заболеваний очень много, то одна лаборатория обычно не может выполнить все необходимые исследования. На сегодняшний день не разработан какой-либо «универсальный» генетический тест, с помощью которого можно было бы выявить абсолютно все генетические заболевания.

Как указано в материалах на сайте EuroGentest, «целью медицинского генетического исследования является предоставление информации о здоровье данного человека или членов его семьи. Как правило, в задачи исследования не входит дополнительная генетическая информация (например, установление отцовства), которая иногда может быть выявлена в ходе исследования» (там же).

Генетические лаборатории могут иметь в штате сотрудников врачей-генетиков, врачей-лаборантов-генетиков, научных сотрудников, младший персонал. Врач-генетик - это специалист с высшим медицинским образованием с дополнительной специализацией по генетике. Пациенты к нему попадают по направлению от самых разных специалистов: терапевтов, кардиологов, акушеров-гинекологов, неврологов, эндокринологов, дерматовенерологов и т. д.

\footnotetext{
${ }^{1}$ В определенной степени такая трактовка может склонять к функционалистской концептуализации термина «ген», потребовавшейся в контексте прорыва к сфере геномики (см.: Wang, 2005).
} 
Врач-лаборант-генетик проводит все необходимые исследования и выдает результат, по которому врач-генетик ставит диагноз и назначает лечение пациенту.

Общение генетиков-специалистов с врачами других специальностей происходит на следующих этапах:

1) консультирования по вопросам направления пациента к врачу-генетику для последующего проведения ДНК-диагностики;

2) обсуждения клинических случаев в рамках консилиума врачей;

3) подготовки совместных работ (конференций, написания статей и тезисов);

4) выдачи заключения лечащему врачу после проведения ДНК-диагностики пациенту;

5) личной заинтересованности врача другой специальности генетикой (например, при чтении им научной литературы, содержащей генетические термины).

В последние годы в медицинской генетике нашла широкое применение технология высокопроизводительного секвенирования или секвенирования нового поколения (Next Generation Sequencing, NGS). Это привело к увеличению числа проводимых исследований, а также широкому обсуждению генетических аспектов врачами других специальностей (не-генетиками). Актуальность обсуждаемой информации создает вокруг каждого генетического понятия ассоциативную связь.

В связи с увеличением масштаба и снижением цены на ДНК-диагностику врачам негенетикам все чаще приходится сталкиваться с результатами генетического тестирования у своих пациентов. Также пациенты могут попросить совета у лечащего врача (терапевта, кардиолога, хирурга и т. д.) в процессе динамического наблюдения за тем, необходимо ли ему генетическое тестирование. Чтобы принимать обоснованные решения, врачам негенетикам необходимы соответствующие знания, их минимальный объем и программы, помогающие в принятии решений.

Таким образом, генетические понятия обсуждаются в коммуникации «врач — пациент», а также «исследователь - клиницист». В данной работе мы рассматриваем сложности понимания генетической информации и клиницистами, и пациентами.

\section{СЛОЖНОСТИ ПОНИМАНИЯ ГЕНЕТИЧЕСКИХ ТЕРМИНОВ ВРАЧАМИ НЕГЕНЕТИКАМИ: СОБСТВЕННЫЙ ОПЫТ}

Наш собственный опыт складывался из общения с врачами других специальностей. На наш взгляд, вопросы (в некоторых случаях - утверждения), 
которые задавали врачи различных специальностей генетикам-исследователям, можно разделить на несколько типов. Мы попытались дать объяснение каждому типу:

1 mип. Вопросы к исследователю: Что такое ген?/ Что такое мутациия? / Что такое сегрегация?

Данные вопросы говорят о том, что врач не сталкивался с генетической терминологией до того времени, когда это стало необходимо. У него есть желание, чтобы ему объяснили каждый термин специалисты, несмотря на то, что данные термины взяты из школьного курса биологии.

2 тип. Часто путают моногенное / полигенное / полиаллельное / мультифакториальное заболевание.

Данные сложности понимания возникают из-за того, что термины комплексные и звучат схоже. Однако, чтобы понять смысл, необходимо просто разложить термин на составляющие: «моногенное» - один ген, «мультифакториальное» - много факторов и т. д.

3 тип. Просьбы к исследователю: Упростите текст... Mbl не поняли, мы показали профессору, он тоже не понял.

Для многих людей характерна черта просить владеющего информацией эксперта о помощи. С развитием геномных технологий владеть информацией могут люди более молодого возраста (по аналогии с развитием Интернета).

4 mun. Вопросы к исследователю: Что такое российская популяциия? Чем наш пациент отличается от иностранного?

Данные вопросы возникают у врачей других специальностей, которые обычно имеют дело с лечением одного пациента, у которого самостоятельно не собирают семейный анамнез. В противоположность этому к врачу-генетику может прийти на консультацию сразу несколько родственников пациента, у которого есть подозрение на наследственное заболевание.

На основании чего были выбраны именно эти гены?

Чаще всего врач другой специальности не интересуется списком геновкандидатов изучаемого им заболевания. В целом это может говорить о непонимании врачами-клиницистами методологии генетических исследований.

5 mип. Вопрос к исследователю: Bbl смотрите только миссенс-мутаuุuu?

Врач заинтересован в генетических данных своих пациентов, однако имеет только отрывочные знания о значении генетических терминов. Обычно такие врачи очень доброжелательно относятся к объяснению терминологии специалистами.

6 mип. Вопросы к исследователю: Что такое гень-кандидаты? / Что такое мажорный /минорный ген? / Какова частота минорного аллеля / фенокопии? 
Несмотря на то, что данные термины являются широкоупотребимыми, они предполагают специальных знаний, чтения самых современных руководств для врачей негенетиков.

В данный тип могут входить вопросы по реинтерпретации генетических вариантов, которые с течением времени поменяли свой «статус» (например, по новым данным выявленный генетический вариант не является мутацией, хотя ранее в научной литературе он был описан именно как мутация).

Реинтерпретация генетических вариантов требует много разъяснений для врачей и пациентов специалистами-генетиками. Доказательная база для интерпретации генетических вариантов постоянно развивается. Следствием этого является то, что клиническое значение варианта может быть со временем переосмыслено по мере появления новых доказательств его патогенности или доброкачественности.

На сегодняшний день, применяют общепринятые критерии для классификации генетических вариантов Американской коллегии медицинской генетики и геномики (American College of Medical Genetics and Genomics, ACMG) (Richards et al., 2015).

ACMG рекомендует широкоупотребимые термины «мутация» и «полиморфизм» заменить на «вариант» со следующими определениями: патогенный (pathogenic), вероятно патогенный (likely pathogenic), вариант неопределенного значения (variant of uncertain significance), вероятно доброкачественный (likely benign) и доброкачественный (benign). Прилагательное «вероятный» используется для обозначения достоверности патогенности или доброкачественности, составляющей более $90 \%$. Однако данное значение известно только специалистам в генетике. Врачи других специальностей без чтения современных генетических и клинических руководств могут интерпретировать такие термины по-своему.

Если генетический вариант с течением времени стали интерпретировать как «патогенный», то это может восприниматься в рамках стигмы: ассоциация генетического варианта с «дефектностью» не только пациентами, но и врачами других специальностей.

Понятие «носительство» часто связывают с виной при передаче варианта потомству, хотя каждый человек является носителем вредоносных, в том числе летальных, генетических вариантов.

7 тип. Вопросы к исследователю: Родственник пациента - это другой пациент? У наших пациентов нет наследственных заболеваний?

Такие утверждения проистекают из отрицания клиницистами возможности того, что их пациенты могут иметь генетическое заболевание. Это может также служить показателем закрытости врачей по отношению к новым знаниям. 
Также врачи других специальностей не всегда понимают, что ДНК-диагностика не обладает исключающей силой. Если у пациента не обнаружена мутация, это не может служить исключением диагноза наследственного заболевания.

Важно отметить, что «методы генетических исследований постоянно совершенствуются, и наши знания о причинах наследственных заболеваний очень быстро расширяются» (Что происходит ..., б/д: Электронный ресурс). Таким образом, если мутация в исследованных генах не была выявлена, есть вероятность, что в ближайшем будущем станет возможным ее выявить в других генах или с применением других генетических методов / технологий.

Также врачи других специальностей не всегда понимают, что ДНК-диагностика требует временных затрат, намного больших, чем обычный анализ крови. На продолжительность анализа влияют следующие факторы: применяемые генетические технологии, размер гена, технические возможности лаборатории. В ряде случаев специалистам требуется провести дополнительное независимое исследование, чтобы проверить первоначальные результаты.

\section{ВЫВОДЫ}

Почему возникают сложности в понимании генетической терминологии? Суммируя данные различных исследований и личный опыт, мы хотим обозначить некоторые предпосылки для возникновения сложностей в понимании терминов и проблем в последующей коммуникации:

1. Генетические термины действительно очень сложны, некоторые из них прошли большой эволюционный путь изменений в интерпретации. Современное понимание термина может отличаться от первоначального.

2. Многие термины, которыми сейчас пользуются специалисты в генетике, дословно переведены с английского, что порой неправильно трактуется неспециалистами в генетике (врачами других специальностей и пациентами). Например, термин «вероятно патогенный генетический вариант» (likely pathogenic genetic variant) воспринимается врачами как: 1) вариант с недоказанной патогенностью; 2) вариант, который обуславливает более мягкую клинику пациента по сравнению с пациентом, имеющим патогенный вариант.

В действительности мы (генетики) в настоящий момент отталкиваемся от наших знаний об изучаемом генетическом варианте.

3. Собственное понимание генетической терминологии, обусловленное генетической грамотностью отдельного специалиста негенетика. Данный показатель может зависеть от специальности врача, его опыта, места работы, личного интереса и увлеченностью генетикой. Также имеет место предвзятое или непредвзятое отношение к новым знаниям. 
Таким образом, в эпоху геномной медицины на восприятие генетической терминологии оказывают влияние:

1) сложности самой генетической терминологии;

2) обыденное понимание и «легенды» вокруг генетических терминов;

3) недостатки в сфере образования;

4) закрытость людей по отношению к новым знаниям.

Такие сложности могут оказывать влияние как на коммуникацию «врач - пациент», так и на взаимодействие «исследователь - клиницист». Среди путей решения данных проблем следует отметить информирование общественности о генетических заболеваниях, а также использование языка, который был бы максимально понятен неспециалистам в генетике.

\section{ОБСУЖДЕНИЕ ВЫВОДОВ}

Здесь я (С. Ю. Шевченко) попытаюсь поместить те выводы, которые выше изложила А. Г. Шестак, в контекст некоторых социальных и биоэтических исследований зарубежных систем здравоохранения и медицинского образования.

Трудности понимания генетических терминов среди широкой общественности фиксируются рядом крупных исследований в течение последних 20 лет. При этом степень знакомства с базовыми понятиями - такими как «ген», «мутация» - достаточно высока (Lanie et al., 2004). Это сочетание и порождает тот феномен, который назван выше А. Г. Шестак «легендами». Сложнее однозначно интерпретировать не раз обозначенные в литературе трудности во внедрении информационных технологий в медицину, связанные с тем, что многие врачи не понимают клинического значения данных генетической диагностики. Для решения такой проблемы предложено снабжать эти данные в электронной карте пациента «информационными кнопками» (Williams et al., 2019). Впрочем, знакомство с определением термина можно считать лишь первым шагом к пониманию его клинического смысла. Необходимы не просто знания, но навыки практического использования генетических данных при принятии клинических решений. В этом широком смысле я и предлагаю понимать указание на восполнение недостатков в «образовании» в третьем пункте выводов. Однако в перспективе массового, рутинного применения фармакогеномики в самых различных сферах здравоохранения можно говорить и о необходимости институциализации генетического образования на лечебных факультетах медицинских вузов (Veilleux, Bouffard, Bourque Bouliane, 2020). 


\section{ПУТИ КОМПЛЕКСНОГО РЕШЕНИЯ \\ ПРОБЛЕМ ПОНИМАНИЯ}

Развитие и масштаб изменений в геномных технологиях создали возможности для новых парадигм лечения и ухода за пациентами в клинике. На сегодняшний день требуют изменений и существующие информационные материалы для врачей и пациентов. Мы видим следующие изменения, происходящие в них:

1. Глоссарии.

Глоссарии с генетическими терминами дополняют новыми терминами, относящимися к типам генетических вариантов и секвенированию нового поколения.

2. Анимационные ролики.

Такие материалы были разработаны не только как образовательный инструмент, но и с целью помощи в принятии обоснованных решений на счет проведения генетического исследования пациентам с наследственными заболеваниями. Ученые из Great Ormond Street Hospital (Лондон, Великобритания) сделали анимационный ролик «Моя последовательность генома» (Lewis et al., 2020). Этот ролик был показан 554 людям в возрасте 11-15 лет в трех школах Великобритании (перед этим испытуемые были проинтервьюированы). Целью было содействие ученых в понимании полногеномного секвенирования у людей молодого возраста. После проведения исследования ученые отметили лучший уровень информированности испытуемых о полногеномном секвенировании. По мнению авторов, такие видеоролики могут служить ценным инструментом для медицинских работников и исследователей, работающих с молодыми людьми в области полногеномного секвенирования.

3. Руководства фондов по определенным заболеваниям.

Такие руководства очень информативны для консультирующих пациентов врачей и родственников пациентов. Они имеют цель обеспечить единый подход к диагностированию и клиническому обслуживанию пациентов с наследственной патологией. Кроме того, они могут помочь в выявлении тех областей, которые требуют дальнейших клинических исследований.

4. Дни об информировании об определенном генетическом заболевании. Примеры: 28 февраля - Международный день орфанных (редких) заболеваний; 23 апреля - Международный день распространения информации о фибродисплазии, известной также под названиями «синдром каменного человека» и «болезнь второго скелета».

Такие дни призваны информировать население о редких генетических заболеваниях, повышать видимость людей с генетическими заболеваниями, способствовать их дестигматизации, а также развивать систему помощи таким пациентам. 


\section{СПИСОК ЛИТЕРАТУРЫ}

Тищенко, П. Д. (2011) Знание, понимание, умение в герменевтической структуре научного текста // Знание. Понимание. Умение. № 1. С. 58-67.

Что происходит в генетической лаборатории? (б/д) [Электронный реcypc] // EuroGentest. URL: http://www.eurogentest.org/index.php?id=506 [архивировано в Wayback Machine] (дата обращения: 31.01.2021).

Широков, А. А. (2019) «По-русски говорите»: сообщение информации и обратная связь во взаимодействии врача-генетика и пациента // Laboratorium: журнал социальных исследований. Т. 11. № 2. С. 125-148. DOI: 10.25285/20781938-2019-11-2-125-148

Cappellen, H. (2018) Fixing language: An essay on conceptual engineering. Oxford ; N. Y.: Oxford University Press. x, 212 p. DOI: 10.1093/oso/9780198814719.001.0001

Carnap, R. (1959) The elimination of metaphysics through logical analysis of language / transl. by A. Pap // Logical positivism / ed. by A. J. Ayer. N. Y. : The Free Press. viii, 455 p. P. $60-81$.

Lanie, A. D. et al. (2004) Exploring the public understanding of basic genetic concepts / A. D. Lanie, T. E. Jayaratne, J. P. Sheldon, Sh. L. R. Kardia, E. S. Anderson, M. Feldbaum, E. M. Petty // Journal of Genetic Counseling. Vol. 13. Issue 4. P. 305-320. DOI: 10.1023/B:JOGC.0000035524.66944.6d

Lewis, C. et al. (2020) Development and mixed-methods evaluation of an online animation for young people about genome sequencing / C. Lewis, S. C. Sanderson, J. Hammond, M. Hill, B. Searle, A. Hunter, C. Patch, L. S. Chitty // European Journal of Human Genetics. Vol. 28. No. 7. P. 896-906. DOI: 10.1038/s41431-019$\underline{0564-5}$

Mol, A. (2002) The body multiple: Ontology in medical practice. Durham, NC ; L. : Duke University Press. xii, 196 p.

Navon, D. (2020) "The gene didn't get the memo": Realigning disciplines and remaking illness in genomic medicine // Critical Inquiry. Vol. 46. No. 4. P. 867-890. DOI: $\underline{10.1086 / 709227}$

Navon, D., Eyal, G. (2014) The trading zone of autism genetics: Examining the intersection of genomic and psychiatric classification // BioSocieties. Vol. 9. Issue 3. P. 329-352. DOI: 10.1057/BIOSOC.2014.18

Nowotny, H., Testa, G. (2010) Naked genes: reinventing the human in the molecular age. Cambridge, MA ; L. : The MIT Press. viii, 144 p.

Richards, S. et al. (2015) Standards and guidelines for the interpretation of sequence variants: a joint consensus recommendation of the American College of Medical Genetics and Genomics and the Association for Molecular Pathology / S. Richards, N. Aziz, S. Bale, D. Bick, S. Das, J. Gastier-Foster, W. W. Grody, 
M. Hegde, E. Lyon, E. Spector, K. Voelkerding, H. L. Rehm // Genetics in Medicine. Vol. 17. No. 5. P. 405-423. DOI: 10.1038/gim.2015.30

Ross, L. N. (2021) Causal concepts in biology: How pathways differ from mechanisms and why it matters // The British Journal for the Philosophy of Science. Vol. 72. No. 1. P. 131-158. DOI: $10.1093 /$ bjps/axy078

Sellars, W. (1962) Philosophy and the scientific image of man // Frontiers of science and philosophy / ed. by R. Colodny. Pittsburgh : University of Pittsburgh Press. 288 p. P. 35-78.

Veilleux, S., Bouffard, M., Bourque Bouliane, M. (2020) Patient and health care provider needs and preferences in understanding pharmacogenomic and genomic testing: a meta-data analysis // Qualitative Health Research. Vol. 30. Issue 1. P. 43-59. DOI: $10.1177 / 1049732319858325$

Wang, D. (2005) "Molecular gene": Interpretation in the right context // Biology and Philosophy. Vol. 20. Issue 2-3. P. 453-464. DOI: 10.1007/s10539-0055584-6

Weiner, K. et al. (2017) Have we seen the geneticisation of society? Expectations and evidence / K. Weiner, P. Martin, M. Richards, R. Tutton // Sociology of Health \& Illness. Vol. 39. Issue 7. P. 989-1004. DOI: 10.1111/1467-9566.12551

Williams, M. S. et al. (2019) Genomic information for clinicians in the electronic health record: Lessons learned from the clinical genome resource project and the electronic medical records and genomics network / M. S. Williams, C. O. Taylor, N. A. Walton, S. R. Goehringer, S. Aronson, R. R. Freimuth, L. V. Rasmussen, E. S. Hall, C. A. Prows, W. K. Chung, A. Fedotov, J. Nestor, C. Weng, R. K. Rowley, G. L. Wiesner, G. P. Jarvik, G. Del Fiol // Frontiers in Genetics. Vol. 10. P. 1059. DOI: $10.3389 /$ fgene.2019.01059

Дата поступления: 08.02.2021 2.

\section{REFERENCES}

Tischenko, P.D. (2011) Znanie, ponimanie, umenie v germenevticheskoi strukture nauchnogo teksta [Knowledge, understanding and skill in hermeneutic structure of scientific text]. Znanie. Ponimanie. Umenie, no. 1. pp. 58-67. (In Russ.).

Chto proiskhodit $\mathrm{v}$ geneticheskoi laboratorii? [What happens in a genetics laboratory?] (s.d.) EuroGentest [online] Available at: http://www.eurogentest.org/index.php?id=248 [archived in Wayback Machine] (accessed 31.01.2021). (In Russ.).

Shirokov A. A. (2019) «Po-russki govorite»: soobshchenie informatsii i obratnaia sviaz vo vzaimodeistvii vracha genetika i patsienta [“Speak Russian!": Information delivery and feedback in geneticist-patient interactions]. Laboratorium. Zhurnal sotsial'nykh issledovanii, vol. 11, no. 2, pp. 125-148. (In Russ.). DOI: $\underline{10.25285 / 2078-1938-2019-11-2-125-148}$ 
Cappellen, H. (2018) Fixing language: An essay on conceptual engineering. Oxford ; New York: Oxford University Press. x, 212 p. DOI: 10.1093/oso/9780198814719.001.0001

Carnap, R. (1959) The elimination of metaphysics through logical analysis of language / transl. by A. Pap. In: Logical positivism / ed. by A. J. Ayer. New York : The Free Press. viii, 455 p. Pp. $60-81$.

Lanie, A. D. et al. (2004) Exploring the public understanding of basic genetic concepts / A. D. Lanie, T. E. Jayaratne, J. P. Sheldon, Sh. L. R. Kardia, E. S. Anderson, M. Feldbaum and E. M. Petty. Journal of Genetic Counseling, vol. 13, issue 4, pp. 305-320. DOI: 10.1023/B:JOGC.0000035524.66944.6d

Lewis, C. et al. (2020) Development and mixed-methods evaluation of an online animation for young people about genome sequencing / C. Lewis, S. C. Sanderson, J. Hammond, M. Hill, B. Searle, A. Hunter, C. Patch and L. S. Chitty. European Journal of Human Genetics, vol. 28, no. 7, pp. 896-906. DOI: 10.1038/s41431$\underline{019-0564-5}$

Mol, A. (2002) The body multiple: Ontology in medical practice. Durham, NC ; London : Duke University Press. xii, 196 p.

Navon, D. (2020) "The gene didn't get the memo": Realigning disciplines and remaking illness in genomic medicine. Critical Inquiry, vol. 46, no. 4, pp. 867-890. DOI: $\underline{10.1086 / 709227}$

Navon, D. and Eyal, G. (2014) The trading zone of autism genetics: Examining the intersection of genomic and psychiatric classification. BioSocieties, vol. 9, issue 3, pp. 329-352. DOI: 10.1057/BIOSOC.2014.18

Nowotny, H. and Testa, G. (2010) Naked genes: reinventing the human in the molecular age. Cambridge, MA ; London : The MIT Press. viii, $144 \mathrm{p}$.

Richards, S. et al. (2015) Standards and guidelines for the interpretation of sequence variants: a joint consensus recommendation of the American College of Medical Genetics and Genomics and the Association for Molecular Pathology / S. Richards, N. Aziz，S. Bale，D. Bick，S. Das，J. Gastier-Foster, W. W. Grody, M. Hegde, E. Lyon, E. Spector, K. Voelkerding and H. L. Rehm. Genetics in Medicine, vol. 17, no. 5, pp. 405-423. DOI: 10.1038/gim.2015.30

Ross, L. N. (2021) Causal concepts in biology: How pathways differ from mechanisms and why it matters. The British Journal for the Philosophy of Science, vol. 72, no. 1, pp. 131-158. DOI: 10.1093/bjps/axy078

Sellars, W. (1962) Philosophy and the scientific image of man. In: Frontiers of science and philosophy / ed. by R. Colodny. Pittsburgh : University of Pittsburgh Press. 288 p. Pp. 35-78.

Veilleux, S., Bouffard, M. and Bourque Bouliane, M. (2020) Patient and health care provider needs and preferences in understanding pharmacogenomic and 
genomic testing: a meta-data analysis. Qualitative Health Research, vol. 30, issue 1, pp. 43-59. DOI: $\underline{10.1177 / 1049732319858325}$

Wang, D. (2005) "Molecular gene": Interpretation in the right context. Biology and Philosophy, vol. 20, issue 2-3, pp. 453-464. DOI: 10.1007/s10539-005$\underline{5584-6}$

Weiner, K. et al. (2017) Have we seen the geneticisation of society? Expectations and evidence / K. Weiner, P. Martin, M. Richards and R. Tutton. Sociology of Health \& Illness, vol. 39, issue 7, pp. 989-1004. DOI: 10.1111/1467-9566.12551

Williams, M. S. et al. (2019) Genomic information for clinicians in the electronic health record: Lessons learned from the clinical genome resource project and the electronic medical records and genomics network / M. S. Williams, C. O. Taylor, N. A. Walton, S. R. Goehringer, S. Aronson, R. R. Freimuth, L. V. Rasmussen, E. S. Hall, C. A. Prows, W. K. Chung, A. Fedotov, J. Nestor, C. Weng, R. K. Rowley, G. L. Wiesner, G. P. Jarvik and G. Del Fiol. Frontiers in Genetics, vol. 10, p. 1059. DOI: $\underline{10.3389 / \text { fgene.2019.01059 }}$

Submission date: 08.02.2021.

Шестак Анна Геннадьевна - научный сотрудник лаборатории медицинской генетики ФГБНУ «Российский научный центр хирургии имени академика Б. В. Петровского»; участник проекта РНФ № 18-78-10132, выполняемого в Институте философии РАН. Эл. адрес: anna.shestak87@gmail.com

SHESTAK, Anna Gennadievna, Research Scientist, Medical Genetics Laboratory, Petrovsky National Research Centre of Surgery; team member of the RSF project No. 18-78-10132 that is being pursued at the Institute of Philosophy, Russian Academy of Sciences. E-mail: anna.shestak87@gmail.com

ORCID: 0000-0002-4596-8950

Scopus AuthorID: $\underline{57204239476}$

SPIN-код РИНЦ: 2301-9841

Шевченко Сергей Юрьевич - кандидат философских наук, научный сотрудник сектора гуманитарных экспертиз и биоэтики Института философии Российской академии наук. Адрес: 109240, Россия, г. Москва, ул. Гончарная, д. 12, стр. 1. Тел.: +7 (495) 697-90-67. Эл. адрес: simurg87@list.ru

SHEVCHENKO, Sergei Yurievich, Candidate of Philosophy, Researcher, Department of Humanitarian Expertise and Bioethics, Institute of Philosophy, Russian Academy of Sciences. Postal address: Bldg. 1, 12 Goncharnaya St., 109240 Moscow, Russian Federation. Tel.: +7 (495) 697-90-67. E-mail: simurg87@list.ru 
ORCID: 0000-0002-7935-3444

Researcher ID: F-5320-2018

Scopus AuthorID: $\underline{57192993265}$

SPIN-код РИНЦ: 2783-6006

Румянщева Виктория Алексеевна - кандидат медицинских наук, врачгенетик ФГБНУ «Российский научный центр хирургии имени академика Б. В. Петровского»; участник проекта РНФ № 18-78-10132, выполняемого в Институте философии РАН. Эл. адрес: vicrumyan@gmail.com

Rumyantseva Victoria Alekseevna, Candidate of Medicine, Clinical Geneticist, Petrovsky National Research Centre of Surgery; team member of the RSF project No. 18-78-10132 that is being pursued at the Institute of Philosophy, Russian Academy of Sciences. E-mail: vicrumyan@gmail.com

ORCID: 0000-0003-3224-8097

Scopus AuthorID: $\underline{36793061200}$

SPIN-код РИНЦ: $\underline{3601-4320}$

Для циитирования:

Шестак А. Г., Шевченко С. Ю., Румянщева В. А. Проблемы понимания результатов генетической диагностики клиницистами [Электронный ресурс] // Горизонты гуманитарного знания. 2021. № 2. C. 37-53. URL: https://journals. mosgu.ru/ggz/article/view/1444 (дата обращения: дд.мм.гггг). DOI: $\underline{10.17805 /}$ ggz.2021.2.3 